\title{
Schizophrenia and Corollary Discharge: A Neuroscientific Overview and Translational Implications
}

\author{
Rujuta Parlikar*, Anushree Bose*, Ganesan Venkatasubramanian \\ WISER Program, Department of Psychiatry, National Institute of Mental Health and Neurosciences, Bangalore, India
}

\begin{abstract}
Corollary discharge mechanism refers to the suppression of sensory consequences of self-generated actions; a process that serves to distinguish between self and non-self based on discrimination of origination of action. It explains, say for example, why we cannot tickle ourselves. This review discusses how corollary discharge model is an essential neural integration mechanism central to the motor functioning of animal kingdom. In this article, research conducted in the field of corollary discharge has been reviewed to understand the neuroanatomical and neurophysiological basis of corollary discharge and gain insight into the biochemical basis of its dysfunction. This review article also explores the role of corollary discharge and its dysfunction in the presentation of symptoms of schizophrenia, discussing the findings from corollary discharge studies on schizophrenia population. Lastly, the link between schizophrenia psychopathology and corollary discharge dysfunction has been highlighted, and an attempt has been made to establish a case for correction of corollary discharge deficit in schizophrenia through neuromodulation.
\end{abstract}

KEY WORDS: Corollary discharge; Efference copy; Motor activity; Auditory hallucination; Transcranial direct current stimulation.

\section{INTRODUCTION}

When we move around in the environment, there are essentially two phenomena that occur with us. These include the sensations that we experience from our own actions, and the sensations which we perceive due to environmental forces that act on us passively. If we weren't able to differentiate these two broad groups of sensations, it would create a significant problem in our understanding of the world. ${ }^{1)}$ This ability to differentiate between selfgenerated activities from the ones resulting from environmental cues is extended over a wide range of sensations. Taking this for instance, when we speak and listen to ourselves, we have the ability to identify the ownership of our

Received: June 7, 2018/ Revised: July 25, 2018

Accepted: August 2, 2018

Address for correspondence: Ganesan Venkatasubramanian, $\mathrm{MD}, \mathrm{PhD}$

WISER Neuromodulation Program, Department of Psychiatry, National Institute of Mental Health and Neurosciences

(NIMHANS), Hosur Road, Bengaluru 560029, Karnataka, India

Tel: +91-80-26995256, Fax: +91-80-26564830

E-mail: gvs@nimhans.ac.in

ORCID: https://orcid.org/0000-0002-0949-898X

*These authors contributed equally to this study as co-first authors. speech. This can easily be discriminated from speech heard from the elements of the outside world. ${ }^{2)}$

If the organism fails to differentiate between sensory impact arising from its own activity versus changes coming from deviations in the sensory environment, this could lead to innumerable challenges in assessing the world. ${ }^{1)}$ For example, with the intentional movement of the eyes or head there would be consequential movement of the retinas. This would cause hurdling of visual scenes one after the other and certain amount of blurring of vision. ${ }^{3)}$ But in reality, the organism is required to experience a change in its visual scenario, only if there is an actual environment modification in the scene. It is certainly expected to experience visual stability when the outside spurs are not present and the organism is simply shifting its gaze voluntarily. Another very interesting phenomenon occurs when an organism is undergoing motion. Linear motion, for example specially targets the otolith organs in the inner ear, which give the organism the sense of motion. But the organism has the ability to identify whether it is moving passively (for example travelling in a train), or actively (for example running a race). ${ }^{4)}$

(ㄷ) This is an Open-Access article distributed under the terms of the Creative Commons Attribution Non-Commercial License (http://creativecommons.org/licenses/by-nc/4.0) which permits unrestricted non-commercial use, distribution, and reproduction in any medium, provided the original work is properly cited. 
The very fact that the brain of an organism is able to establish this differentiation is consequence of its ability to monitor its own movements. This differentiation is achieved by generation of efference copies of its motor commands by the brain and transmitting them to its sensory reception structures. When these efference copies match the incoming reception of consequences of self-generated action, there occurs a suppression of the sensation arising from perceiving one's own action, this phenomenon is known as corollary discharge. ${ }^{5)}$ Corollary discharge is the estimation made by the brain that enables it to predict the likely sensory consequences of its motor activities; this, in turn, helps the organism in establishing the difference between self and non-self. 6 )

\section{COROLLARY DISCHARGE}

\section{Definition}

Corollary discharge is an integration mechanism that embodies the core principle of neural functioning in most of the species. ${ }^{1)}$ It can be defined as a neural integration mechanism with two most essential functions of the suppression of sensations resulting from the organism's own actions, and discreet learning of the ability to predict future events based on the present subset of events.

It has been fervently postulated that the ability to establish the concept of self and non-self is not simply restricted to the assessing of sensory inputs in the context of motor movements, but it also incorporates complex higher mental functions like thought and consciousness that, in principle, retain the features central to motor mechanisms. ${ }^{7)}$ Studies have proven that the ownership of a thought involves a neural circuit, in which, corollary discharge plays an important part in the process of rendering the consciousness to a particular thought. ${ }^{8)}$

Though in literature the terms 'efference copy' and 'corollary discharge' have been used sometimes interchangeably, it is pertinent to draw a distinction between the two. As elucidated previously, ${ }^{9,10)}$ any action is preceded by transmission of a blueprint of the intended action plan to sensory cortex from the frontal areas of brain responsible for planning. This blueprint carrying the details about expected sensory consequences of intended action is referred to as efference copy. Actual sensation experienced on reception of self-generated action is denoted as 'sensory reafference'. The brain, while executing the movement, effectively subtracts the 'expected' sensations from 'experienced' sensations; this manifests as a net suppression of sensory awareness when actions are selfgenerated. This sensory suppression is referred to as corollary discharge., ${ }^{9,10)}$

\section{Historical Background and Evolutionary Implication}

Corollary discharge has been a topic of intrigue and research since long in the scientific community. This neural integration mechanism was extensively studied for the first time in the field of visual perception. ${ }^{11)}$ It was put forth, that there is a motor command that is sent to the sensory structures for evaluating the sensory feedback generated from the activities of a fish's eye movement. Sperry ${ }^{11)}$ named this phenomenon as "corollary discharge". Another study conducted around the same time by scientists von Holst and Mittelstaedt, ${ }^{12)}$ evaluated the concept of 'efference copy command' that is essentially similar to the corollary discharge suggested by Sperry. ${ }^{11)}$ In years that followed, several studies were conducted to understand this mechanism, directly and indirectly. For instance, one study reviewed the integration of all motor commands, its corollary discharge and the perception generated from such movements under one set up. ${ }^{13)}$ Several other studies briefly touched upon and considered the concept of corollary discharge mechanism. ${ }^{14,15)}$ The concept of this feedback circuit related to corollary discharge was studied in the context of visual perception to the most extensive degree. ${ }^{16-19)}$ Corollary discharge circuit in sensory perception was also gauged by other research groups. ${ }^{20)}$ The history of the examination of the corollary discharge phenomenon spans from the 1900s to this date; in contemporary research newer studies with substrates like eye-movement or event-related potential correlates are opening up a whole new avenue for further imploring and examination of this context.

Studies found that organisms that fail to develop this complex neural integration mechanism of corollary discharge are at an evolutionary disadvantage, since their own activities jar their perception of the outside world, lending them to extinction. The importance of the development of these complex feedback signals comprising the corollary discharge phenomenon is thus signified, extending from invertebrates to vertebrates, with an increase in degree of complexity up along the taxonomical ladder of animal kingdom. ${ }^{1)}$ 


\section{The Neurophysiology of Corollary Discharge}

Neurophysiological findings indicate that animals constantly update themselves with the sensory consequences of their own motor commands so that they are able to distinguish the sensory consequences of their own activity from that of the passive sensory reception from environmental activity. This ability of the organisms on account of their corollary discharge signals is mediated by specific set of neurons. ${ }^{21)}$ For instance, among crickets, the auditory reception remains suppressed during the act of their own singing, thus preventing them from undergoing auditory damage from constant noise they create. This inhibition was found to be brought about by a neuron identified as corollary discharge interneuron (CDI). ${ }^{21)}$ These CDI mediate the presynaptic inhibition of auditory sensations and also lead to post synaptic inhibition of the auditory interneuron which leads to decreased auditory reaction to sounds produced by the organism. The process of corollary discharge prevents an organism (like cricket or bullfrog) from getting desensitized to its environment because of sensory saturation from receiving its own near constant noise. In addition to this the corollary discharge is also responsible for increasing the sensitivity of the sensory neurons to external stimuli occurring interim. ${ }^{21)}$

Studies report that when any movement is initiated, the copy sent from the motor command is compared with the reafference or the sensory outcome of the movement. If they both are comparable with no difference, no further motor adjustment of the movement is done. But instead, if any minute change is observed, the brain tries to identify if the difference is on account of some external stimuli or is due to lack of corrective compensatory mechanism. ${ }^{8)}$ It has also been suggested that the corollary discharge mechanism has an evolutionary advantage over regular proprioceptive feedback mechanism since it also predicts future movements thus preparing the organism for a varied stimuli response pattern. ${ }^{22)}$

Neurophysiological evidences show that when the efference copy of motor command matches the sensory feedback (reafference copy) for a particular movement, there is a resonant increase in the gamma oscillations; this increased gamma oscillations might underlie the brain's inference of this motor command as self-generated; on the contrary, if there is a mismatch between reafference and efference copies even by minute degrees, gamma oscillations decrease; this might result in the brain inferring this latter scenario as a externally generated event. Such neurophysiological changes subserve the organism's ability to differentiate between activity of self and non-self. ${ }^{23)}$ In tune with these observations, findings implicate an increase in gamma oscillations between frontal and temporal lobes during the act of talking as against the act of passive listening. ${ }^{24)}$

Evidences indicate that corollary discharge mechanism plays a crucial role in the context of understanding of self and non-self in higher motor tasks like thought or consciousness. Corollary discharge phenomena speeds up the process whereby the attention signal generated accesses the working memory at the time when a thought is being focused there. Corollary discharge phenomena is also implicated in correction of directional attention when there is a discrepancy between the expected and the actual consequence arising from an action (for example, it plays a role in inhibiting distractors which engage an organism thereby deviating their attentional focus away from a particular object or phenomena of interest). ${ }^{8)}$

\section{Neuroanatomical Basis of Corollary Discharge}

Several studies have probed into the understanding of the anatomical structures that could be responsible for the corollary discharge phenomenon. Most common finding is the activity in fronto-temporal circuits responsible for attenuation of auditory response to self-generated sounds. ${ }^{25)}$ Some studies have also found cerebellum to be playing an important role in the comparison between a prediction and actual activity. ${ }^{25,26)}$ It is postulated that cerebellar-parietal connection establishes the difference if any between predicted outcome of an activity and the actual outcome of the activity, so that compensatory mechanisms can be initiated. Some studies have reported evidences implicating ventrolateral and mediodorsal nuclei of the thalamus in the processing of corollary discharge phenomena in human patients with lateral thalamic lesions. ${ }^{6}$ While the corollary discharge in the auditory pathway is mediated through the arcuate fasciculus that connects the frontal and temporal cortical areas, ${ }^{27)}$ the corollary discharge in the visual saccadic movements is brought about by superior colliculus-mediodorsal thalamus and frontal eye field pathway utilizing the process of coordinating and stabilizing vision across saccades. Findings further suggest that these circuits for corollary discharge in the visual saccadic movements extend from 
extra-ocular motor neurons right up to the cerebral cortex. $^{28)}$

Based on the putative neuroanatomical substrates, the phenomenon of corollary discharge has been classified into lower order categories (performing reflex inhibition and sensory filtration) and higher order categories (sensory analysis and sensorimotor learning/planning by experts). ${ }^{1}$ It was surmised that corollary discharge plays an important role in preventing an organism from undergoing a reflex activity in effect of its own actions at lower level of functioning, and this underlies its ability to acquire sensorimotor learning; for example, a bird fine tuning its tones using sensory feedback obtained from the corollary discharge, from its memory. An example of reflex inhibition and sensory filtration from corollary discharge mechanism can be seen in Pleurobranchaea, a gastropod, organism with simpler nervous system. Pleurobranchaea exhibits repulsion if the tactile mechano-receptors of its oral veil are activated on contact with an external stimulus. But activation of the same tactile mechano-receptors at the time of its feeding activity, does not lead to any repulsion. The study comments that it occurs as a result of corollary discharge interneuron activity that silences the reflex withdrawal of the gastropod during its self-generated activity, in this case being feeding.

Role corollary discharge mechanism in sensory analysis and sensorimotor learning and planning has been documented in organisms with complex nervous system as well. A study examining the neuroanatomical functioning of bats, specifically, Rhinolophus rouxii, which sends sonic signals for hunting and estimating obstacles in its path, indicated that corollary discharge mechanism mediated their sonic navigational system. The corollary discharge mechanism served to a) match the echo received by the receptor centre in the inferior colliculi with the efference copy generated and sent by the bat's vocalization centre, and b) examine whether the actual echo is received in the expected time window; failing which, the source of the echo is labelled as external. Such higher order analyses through corollary discharge mechanism gives this animal the ability to estimate the location, size and speed of the object (self or non-self) that is causing the echo. In higher order complex motor functions like thoughts, ${ }^{7)}$ studies have evaluated the ballistic control model of attention, suggesting that defect in the attention is responsible for disturbance in consciousness. ${ }^{8)}$ Areas like prefrontal cortex are responsible for goal directed thoughts while superior parietal lobule and temporal parietal junction are responsible for the generation of attention signal. These two areas are believed to be responsible for stimulating the attention signal while inhibiting the distractions. Visual cortex is responsible for focused attention on the target thought, while the corollary discharge is meant for targeting a buffer space where the attention can be temporarily focused. ${ }^{8)}$

\section{Neurochemical Basis of Corollary Discharge}

Analysis of population with dysfunctional corollary discharge mechanisms (patients of schizophrenia, ${ }^{29)}$ for instance) indicates a possible role of abnormal levels of different neuro-modulators like dopamine, acetylcholine, $\gamma$-aminobutyric acid, glutamate of the many others as one of the few causative factors. ${ }^{8,30)}$ However among this group of neurotransmitters, there is compelling evidence for acetylcholine to play a crucial role in corollary discharge feedback circuits. ${ }^{31)}$ It has been proposed that acetylcholine aberrations might underlie the disruption of corollary discharge. ${ }^{32)}$ Another postulates that corollary discharge, which is mediated as a feedback through the internal association fibres in the neural circuit is inhibited by cholinergic inputs. ${ }^{8)}$ Acetylcholine is essentially balanced in the brain, but if increased, may lead to complete shutting of the corollary discharge feed forward feedback, leading to dispersion of attention to varied stimuli and loss of the ability of identification of an activity as an action of self. $^{33)}$

\section{COROLLARY DISCHARGE IN THE CLINICAL DISORDERS}

As a neural integration mechanism, the study of corollary discharge mechanism has not just been restricted to physiology; its contribution to clinical pathology has also been examined. Several studies have found this feed forward phenomenon to be integral to appropriate perception and prediction, and its malfunction manifests itself in the form of several diseases.

Among movement disorders, bradykinesia has been studied. Bradykinesia is a slowing of the limb movements as seen in parkinsonism, a neurological disorder which is categorized by the disintegration of dopaminergic neurons of the basal ganglia. ${ }^{34)}$ One study found that the 
movement disorder occurs on account of misjudgment during the limb movement. In these patients, there is inappropriate coordination between the proprioceptive sensory feedback and the corollary discharge mechanism operating at the higher centres. As the patient is unable to predict the position of the limb, it results in slowing of his limb movement leading to bradykinesia. ${ }^{35)}$

Cerebellar disorders have also been studied to evaluate if corollary discharge plays any role in the typical presentation like usage of the index finger or performing actions of opposition. ${ }^{36)}$ Actions like apposition of thumb require well-coordinated, sequential functioning of muscle movements. It has been suggested that disruption to pyramidal tracts to the cerebellum responsible for corollary discharge dysfunction, can account for lack of practiced, harmonized progressive movement tasks.

Certain ownership disorders like anarchic hand syndrome in which there is perceived loss of control over a limb. ${ }^{37)}$ Utilization syndrome in which the patient is completely dependent on the external stimuli for perception of the world ${ }^{38)}$ and alien hand syndrome in which the patient completely denies the ownership of his/her limb have been studied. ${ }^{39)}$ One of the studies probed into the possible reasoning behind the specific presentation of these disorders and postulated that it could be on account of lack of coordination between the sensory feedback mechanism and the corollary discharge feed-forward circuit. $^{40)}$

In one neurophysiological study conducted on the phrenic nerve activity of a cat, observations indicated that corollary discharge mechanism plays an important role in moderating the activity of the phrenic nerve outflow rhythms. ${ }^{41)}$ The study found that in spite of splitting the brain stem of the cat, rhythms of the two phrenic nerves could be harmonized. This is believed to be due to the circuit that integrates with sensory feedback from the contralateral phrenic nerve activity.

A common neurodegenerative condition, Alzheimer's disease ${ }^{42)}$ has been found to have notable memory deficits in its primary phase. ${ }^{43)}$ Few studies have suggested that one of the features of memory impairment in Alzheimer's disease is that inherent (implicit) memory is used to recall explicit (freshly sort out information) memory. ${ }^{44,45)}$ It has now been put forth, that sensorimotor integration errors in the form of prediction errors in task outcomes are common presentation of these patients dur- ing the act of recall of memories. ${ }^{46)}$ This is believed to be on account of feed-forward or corollary discharge mechanism dysfunction.

In psychiatric disorders, potential corollary discharge dysfunction in autism spectrum disorder has been studied. Autism is a neuro-developmental disorder which presents with uncharacteristic development in socialization, interaction and mannerisms and conduct. ${ }^{47)}$ A study conducted in understanding its symptomatology has found that the one of the possible pathogenetic basis for autism is that the neural integration of sensations from multiple inputs is impaired in these individuals. ${ }^{46)}$ This defect is responsible for failure in comprehending and predicting patterns of movements at the higher centres. Perhaps, secondary to these corollary discharge deficits, patients find it difficult to anticipate the consecutive actions of their initiated movement. The study emphasizes on the possible role of dysfunction of the feed forward circuit.

Undoubtedly, all the above-mentioned disorders and physiological dysfunctions occurring on account of impaired corollary discharge mechanism are noteworthy. But it requires special mention that lack sense of self, inability to identify activities self-generated by the body, and the sense of attention for tasks at hand are perhaps most profoundly affected in the psychiatric disorder schizophrenia. ${ }^{8)}$ Many empirical studies have evaluated the impact of corollary discharge impairment on schizophrenia patients (Table 1).

\section{COROLLARY DISCHARGE IN SCHIZOPHRENIA}

\section{Brief Overview}

Schizophrenia is a complex psychiatric disorder that is known to affect approximately $0.3 \%$ to $0.7 \%$ of the population worldwide. ${ }^{48)}$ Inability to distinguish between thoughts and actions generated from self and others, which is a core component of schizophrenia ${ }^{8)}$ has been postulated to be secondary to the failure of corollary discharge mechanism. ${ }^{15,49)}$ Corollary discharge dysfunction in schizophrenia has been explored through numerous methods in the last few decades. Methods primarily employed for tracking this corollary discharge circuit include functional magnetic resonance imaging ${ }^{50)}$ and event related potentials. ${ }^{51-53)}$ Few studies have used the smooth muscle pursuit task for studying the prediction factor of 
Table 1. Summary of studies on corollary discharge deficit in schizophrenia (SCZ) patients with auditory hallucination in comparison to healthy controls

\begin{tabular}{|c|c|c|c|c|}
\hline Study & Factor & Healthy control & SCZ & Implication \\
\hline $\begin{array}{l}\text { Ford et al., } \\
\text { 2002; ERP } \\
\text { study }\end{array}$ & $\begin{array}{l}\text { Gamma coherence } \\
\text { between frontal \& } \\
\text { temporal lobes }\end{array}$ & $\begin{array}{l}\text { Greater frontal-temporal } \\
\text { coherence during talking } \\
\text { than listening }\end{array}$ & Not seen & $\begin{array}{l}\text { Frontal-temporal } \\
\text { disconnection in SCZ }\end{array}$ \\
\hline $\begin{array}{l}\text { Ford et al., } \\
\text { 2001; ERP } \\
\text { study }\end{array}$ & N100 amplitude to self-talk & Attenuated & Inadequate attenuation & $\begin{array}{r}\text { Lack of suppression of PAC } \\
\text { during self-speech in SCZ }\end{array}$ \\
\hline $\begin{array}{l}\text { Heinks-Maldo } \\
\text { nado et al., } \\
\text { 2007; ERP \& }\end{array}$ & $\begin{array}{l}\text { Feed forward model of } \\
\text { self-initiated activity }\end{array}$ & $\begin{array}{l}\text { Graded suppression of N100: } \\
\text { N100 Sup. to unaltered voice } \\
\text { >altered voice }\end{array}$ & $\begin{array}{l}\text { Absence of Graded } \\
\text { suppression of N100 }\end{array}$ & $\begin{array}{l}\text { Deficient forward model in } \\
\text { SCZ; AVH result from } \\
\text { "misperception" }\end{array}$ \\
\hline DTI study & $\begin{array}{l}\text { Structural deficits in } \\
\text { arcuate fasciculus }\end{array}$ & Insignificant & Pronounced & $\begin{array}{l}\text { Damage to brain's architecture } \\
\text { adds to CD dysfunction in SCZ }\end{array}$ \\
\hline $\begin{array}{l}\text { Ford et al., } \\
\text { 2008; EEG } \\
\text { study }\end{array}$ & $\begin{array}{l}\text { Pre-movement / action } \\
\text { synchrony in response } \\
\text { to button press }\end{array}$ & $\begin{array}{l}\text { Maximal gamma-beta } \\
\text { synchrony over contralateral } \\
\text { sensori-motor cortex }\end{array}$ & $\begin{array}{l}\text { Reduced gamma-beta } \\
\text { synchrony over } \\
\text { sensori-motor cortex }\end{array}$ & $\begin{array}{l}\text { Efference copy/CD deficit } \\
\text { across modalities in SCZ with } \\
\text { AVH }\end{array}$ \\
\hline $\begin{array}{l}\text { Whitford et al., } \\
\text { 2011; } \\
\text { Neuro-physi }\end{array}$ & $\begin{array}{l}\text { Delayed feedback (graded) } \\
\text { to self-initiated act }\end{array}$ & $\begin{array}{l}\text { CD disrupted in response to } \\
\text { delayed feedback }\end{array}$ & $\begin{array}{l}\text { CD corrected upon delayed } \\
\text { feedback (at } 50 \mathrm{~ms} \text { ) }\end{array}$ & $\begin{array}{l}\text { Time lag in arrival of efference } \\
\text { copy to sensory cortex in } \\
\text { SCZ; result-CD deficit }\end{array}$ \\
\hline $\begin{array}{l}\text { ological and } \\
\text { diffusion } \\
\text { tensor } \\
\text { imaging study }\end{array}$ & $\begin{array}{l}\text { Structural deficits in arcuate } \\
\text { fasciculus for cortical sup. } \\
\text { across delayed feedback } \\
\text { conditions }\end{array}$ & $\begin{array}{l}\text { Linear relationship between FA } \\
\text { in the arcuate and pattern of } \\
\text { N1 suppression across delay } \\
\text { conditions }\end{array}$ & $\begin{array}{l}\text { Inadequate FA in the arcuate } \\
\text { fasciculus }\end{array}$ & $\begin{array}{l}\text { Evidence supports fronto- } \\
\text { temporal disconnection } \\
\text { hypothesis in SCZ }\end{array}$ \\
\hline $\begin{array}{l}\text { Spering et al., } \\
\text { 2013; Eye } \\
\text { movement } \\
\text { study }\end{array}$ & $\begin{array}{l}\text { Effect of abnormal pursuit } \\
\text { on Prediction } \\
\text { performance }\end{array}$ & $\begin{array}{l}\text { Better trajectory prediction with } \\
\text { pursuit; performance enhanced } \\
\text { with increase in duration of } \\
\text { stimulus presentation; } \\
\text { correlation between pursuit } \\
\text { gain \& pursuit judgment }\end{array}$ & $\begin{array}{l}\text { Poor trajectory prediction; } \\
\text { No pursuit advantage with } \\
\text { increased presentation; no } \\
\text { correlation }\end{array}$ & $\begin{array}{l}\text { SCZ patients have intact early } \\
\text { sensory (visual processing), } \\
\text { but fail to use efference copy } \\
\text { signal. Sensory systems have } \\
\text { impaired efference signal }\end{array}$ \\
\hline $\begin{array}{l}\text { Shergill et al., } \\
\text { 2014; fMRI } \\
\text { study }\end{array}$ & $\begin{array}{l}\text { Attenuation of } \\
\text { self-processing }\end{array}$ & $\begin{array}{l}\text { Attenuated activation in } \\
\text { secondary somatosensory } \\
\text { cortex; sensation and action } \\
\text { were synchronous }\end{array}$ & $\begin{array}{l}\text { Absence of or inadequate } \\
\text { attenuation of activity in } \\
\text { secondary somato-sensory } \\
\text { cortex }\end{array}$ & $\begin{array}{l}\text { SCZ patients are unable to } \\
\text { predict the sensory } \\
\text { consequence of their own } \\
\text { actions; deficient CD }\end{array}$ \\
\hline
\end{tabular}

ERP, event related potential; PAC, primary auditory cortex; DTI, diffusion tensor imaging; $\mathrm{AVH}$, auditory verbal hallucinations; $\mathrm{CD}$, corollary discharge; EEG, electroencephalography; FA, factional anisotropy; $\mathrm{FMRI}$, functional magnetic resonance imaging.

corollary discharge. ${ }^{54)}$ Though most neurophysiological studies have focused on role of corollary discharge dysfunction in the pathophysiology of auditory hallucinations in schizophrenia (summarized in Supplementary Table 1; available online only), these studies on corollary discharge in schizophrenia are diverse in the questions they posed to answer.

One of the studies that was conducted to understand the self-disturbances in schizophrenia enlisted two primary elements of distortions, namely i) hyper flexibility which leads to excessive attention towards self-features as though they were external, and ii) reduction is self-affection, which is diminished understanding of one's presence ${ }^{55)}$ From the perspectives of operationalized clinical manifestations, these self-disturbances are described as positive symptoms such as delusions and hallucinations and negative symptoms like affective flattening, avolition, alogia, anergia, and anhedonia constitute the major diagnostic criteria. However, apart from these pivotal presenting symptoms, schizophrenia patients are also known to suffer from cognitive deficits like disturbances in attention, working memory, and certain executive functions. This cluster of mental and physical manifestations leaves a patient in a state of personal and social jeopardy which is associated with a life long suffering. ${ }^{56)}$

Contextually, it is interesting to note that studies have found that disturbances in stream of consciousness or derealization with loss of contact from self are also on account of disturbed corollary discharge activity. Corollary discharge buffer activity is required to focus all attention on an object of interest giving the individual a conscious focused experience. It has been put forth that reduction in 
the activity of this discharge buffer is responsible for causing distortion and bringing to attention varied stimuli that the person finds difficult to assemble into one level of consciousness (Fig. 1). ${ }^{8)}$

Studies investigating possible causes for the disruption of corollary discharge in disorders like schizophrenia, have postulated that the possible role of decreased myelination of tracts in the brain could be the cause of delayed corollary discharge mechanism in neural circuitry. ${ }^{30}$ Several studies have probed into understanding the link between auditory hallucinations and deficient corollary discharge. It has been demonstrated that in healthy people, corollary discharge released from the motor speech areas of frontal lobe, act on the auditory cortex preparing it for the sensations of its self-generated activity that gives an individual the ability to establish its self from non self. ${ }^{27)}$ Recent findings suggest that in schizophrenia patients this process is disrupted as reflected in specific differences observed in structural architectural and neurophysiological activity of the schizophrenia patients in comparison to healthy controls (Table 1). Based on these observations, it has been surmised that such disruption of this corollary discharge is responsible for the auditory hallucinations in schizophrenia.

Delusions are false beliefs that suggest of an abnormality in the affected individual's thought process and judgement, which cannot be accounted for through logical reasoning. The most important part of it is the degree to which the individual holds the belief as true, in spite of presenting contrary evidence. ${ }^{57 /}$ Studies have now found that these occur on account of disruption of the corollary discharge ${ }^{58)}$ which, under normal circumstances is responsible for higher motor planning, prediction and learning. ${ }^{1)}$ As there is loss of ability to use learned memory to infer understanding of current situation, patients engage in convenient explanations ${ }^{59-61)}$ that bring them relief, hence they hold on to them. ${ }^{62)}$ These beliefs are then used to deduce future experiences of the patient that constitute a part of the psychopathology itself. ${ }^{63)}$

Patients suffering from schizophrenia may present with language disturbances like incoherence and pressure of speech, tangentiality or derailment. Studies examining these features report that the disruption of corollary discharge, which is responsible for the inhibition of distractions during attention focusing, leads to disintegrated emphasis on a singular biased object. The patient finds oneself subjected to varied stimuli that bring about the classic presentation of formal thought disorder in these patients. ${ }^{8)}$ Symptoms like thought insertion present in schizophrenia are thus postulated to be a result of defective corollary discharge mechanism. ${ }^{64)} \mathrm{A}$ study claimed that the lack of ownership of a thought occurs on account of lack of efference copy to the attention bias. Since patients experience a thought or a sensation from an activity that is self-generated, but there is no efference copy, they misconstrue their thought or activity as a result of outside forces or as non-self. ${ }^{64)}$

Another intriguing symptom of schizophrenia is that of somatic passivity or passivity phenomena. Essentially, in a healthy individual, an act of holding a pen and writing on

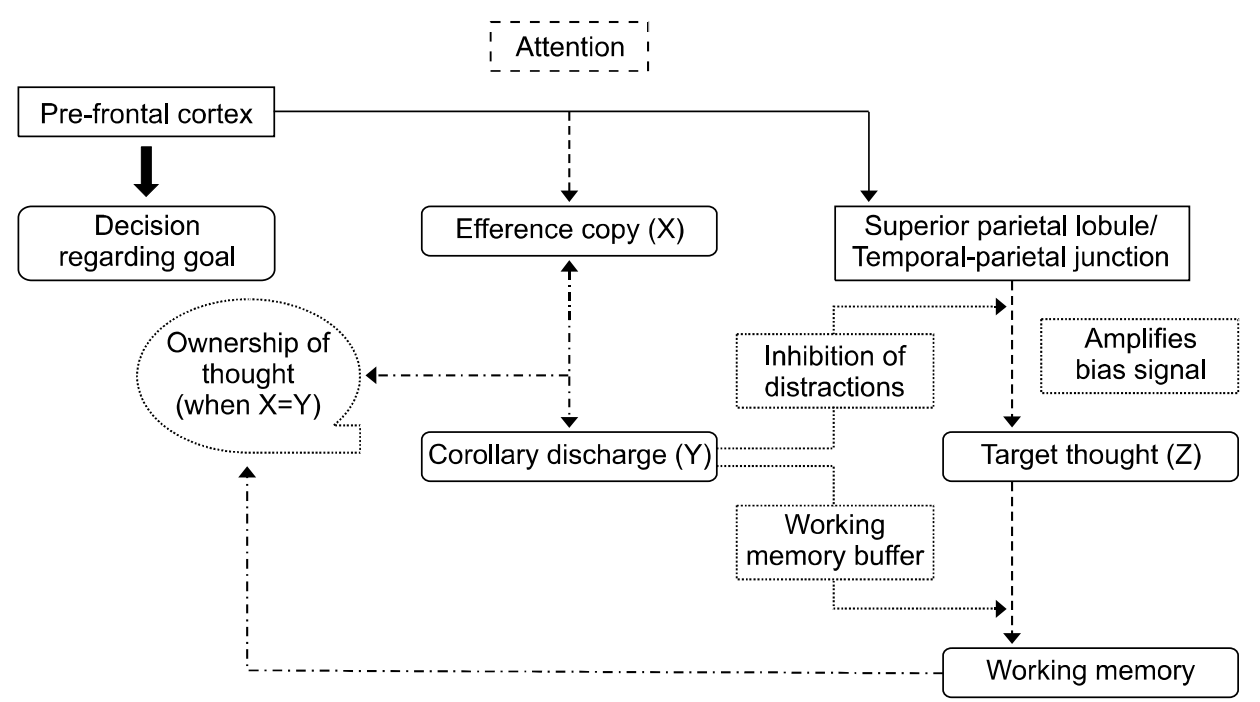

Fig. 1. Corollary discharge feedback mechanism. If $X$ equals $Y$, efference copy (estimation) and afference feedback complement; so, no neural activity is changed and the activity is identified as 'Self'. If $X$ does not equal $\mathrm{Y}$, assessment is done to evaluate if there is (i) inappropriate compensatory mechanism, or (ii) external influence on activity. 
a piece of paper has two components. One that, he has the desire to conduct such an activity, and when it is being accomplished, he has the acknowledgement of the activity being self-generated. In the context of passivity experience, schizophrenia patients will attribute the agency of their own volitional act to an external force; thus, patients with passivity symptoms will report that a non-self agent control their actions, thoughts and sensations. For instance, they would use the pen to write something, but wouldn't be able to acknowledge that it was their volitional act, but rather an activity of an external agency. The study postulated that, on account of lack of an efference copy to the sensory system, the patient is in an unfortunate position to unable to predict the positional errors of its limb and correct them before the peripheral feedback arrives. Hence, though the patient is aware of the executed action, he is unaware of being the initiator of the same. ${ }^{65,66)}$ To understand the neural correlates of passivity symptoms, proprioceptive function has been examined in schizophrenia patients suffering from passivity phenomena. It has been demonstrated that proprioception (as examined by self-induced attempt at tickle) too is affected in schizophrenia patients in comparison to healthy controls who were able to tickle themselves unlike the healthy individuals. $^{26)}$

Studies have delved into examining the causative factors believed to be responsible for corollary discharge involving prediction and its anatomical and physiological basis. Patients demonstrating corollary discharge dysfunction have disturbances in neural myelination. Decreased myelination in white matter leads to delay in the conduction of impulse to sensory areas thus contributing to lack of sensory feedback eventually affecting person's concept of "self". ${ }^{30)}$ Alongside decreased myelination, aberrations in acetylcholine level have been postulated to explain both symptoms of schizophrenia and corollary discharge dysfunction. ${ }^{31)}$ Abnormally increased levels of acetylcholine might underlie symptom presentation in schizophrenia; a related conceptualization of the neural model in schizophrenia posits an interaction between cholinergic aberrations and thalamus. ${ }^{8)}$ Thalamus relays both attentive stimuli and distractions. Acetylcholine acting on the nicotinic receptors of the thalamus regulates the neural activity of information processing by engaging attention. Acetylcholine acting on the muscarinic receptors of the association fibres, suppresses their activity, hence preventing the inhibition of distractor stimuli. Corollary discharge is inhibited by such excess of acetylcholine that leads to gradual 'loss of self' experienced by schizophrenia patients with the genesis of Schneiderian first rank symptoms (this includes thought alienation, somatic passivity and related similar experiences). ${ }^{67)}$ The increased acetylcholine contributes to attention deficit by inhibiting monitoring activity of prefrontal cortex; this in turn sets up the platform for the onset of negative symptoms and cognitive decline on account of prefrontal inhibition. With on-going increase in the acetylcholine neuromodulator, complete disintegration of the "concept of self" occurs as the disorganization syndrome presents itself. ${ }^{8)}$

\section{Corollary Discharge, Dreams and Hallucinations}

Similarities between sleep-related experiences and hallucinations have been a matter of legitimate scientific curiosity that has led to examination of two processes in relation to each other. ${ }^{68)}$ Dreams and other sleep related experiences like hypnagogia share some overlapping features with hallucinations-1) subjective descriptions like complexity, emotional charge and acceptance of bizarre or implausible scenarios, etc.; and 2) underlying neural mechanism. ${ }^{69)}$ However, there exist crucial and clear differences between the two on phenomenological features and neural mechanisms. While dreams and hypnagogia are multisensory experiences with visual modality dominating the presentation, in schizophrenia, hallucinations are mostly auditory. In dreams, the experience happens in external world and the person attributes the process of dreaming to self. In schizophrenia, hallucination is cloaked with veridical perception; they are concurrent with the ongoing mental processing. Dreams are often not recalled upon wakefulness and they rarely affect a person's experience of himself; hallucinations occur in wakefulness, and they are not only remembered well but they often interfere with a person's understanding of himself and world he lives in (for details see review ${ }^{68)}$ ). Interestingly, corollary discharge, being integral to the sensory-motor systems of consciousness, is common to both of these experiences - dreams and hallucinations. It has been reported that corollary discharge or feed forward circuits are temporarily suppressed during the act of sleeping in normal healthy brains. ${ }^{69)}$ It has been further posited that the level of cortical suppression (that occurs 
through execution of corollary discharge) accounts for the differing experience of the dreamer; the greater the suppression of corollary discharge or feed forward circuits during sleep, more vivid and immersive is the dreaming experience. ${ }^{69)}$ In both dreaming (along with associated sleep related experiences) and hallucinations, thalamus activation regulated by acetylcholine activity plays a crucial role. Acetylcholine directs the focus of mind inwards, creating an attentional bias towards internal experiences that is required to perpetuate experiences like dreaming and hallucinations. ${ }^{70)}$ Similar limbic activity has been shown to underlie affective components of hallucinations and emotional component of dreaming. ${ }^{70)}$ These evidences can guide fine tuning of clinical definition of hallucinations as "overlaid on veridical perceptions" (because dreams are non-veridical perceptions and unbidden experience too) ${ }^{68)}$ and provide leads for novel clinical treatments ${ }^{69)}$ that target neural mechanisms responsible for such unbidden, vivid and affective perceptual experiences.

\section{Neuromodulation of Corollary Discharge in Schizophrenia}

Transcranial direct stimulation (tDCS) operates on the concept of utilizing weak intensity direct current to modulate cortical excitability. Several studies have examined and reported effectiveness of tDCS neuromodulation treatment for refractory symptoms of schizophrenia (see review $^{71)}$ for details), particularly refractory auditory hallucination. ${ }^{72,73)}$ Two studies among these have explored effect of neuromodulation with tDCS on corollary discharge mechanism among schizophrenia patients with persistent auditory hallucination. In schizophrenia patients with persistent auditory verbal hallucinations, add-on tDCS (in open-label design) resulted in significant reduction of auditory hallucination severity with concurrent amelioration of corollary discharge deficit. ${ }^{74)}$ This observation was replicated recently in randomized, double-blind, sham-controlled design; importantly, the magnitude of cortical suppression during corollary discharge had a significant positive correlation with reduction in auditory hallucination scores. ${ }^{75)}$ These observations are in conformation with previous report of neuroplastic effect of tDCS enhancing auditory processing efficiency. ${ }^{76}$ It is possible that fronto-temporo-parietal tDCS reduces auditory hallucination severity by addressing aberration in corollary discharge mechanism possibly through adaptive modulation of neuroplasticity; potentially, both anodal stimulation to left dorsolateral prefrontal cortex and cathodal stimulation to temporo-parietal junction facilitates these changes. ${ }^{75)}$

\section{FUTURE RECOMMENDATIONS}

Corollary discharge is a crucial neural integration that gives an organism the ability to identify active undertakings from passive activities. It is released from the motor areas of the brain, carrying efference copies of its expected sensory outcomes. Despite the extensive body of research available on corollary discharge mechanism, certain areas require further understanding. ${ }^{1)}$ The corollary discharge activities in olfactory and gustatory components of sensory apparatus haven't been explored adequately. As far as vestibular feedback is concerned, corollary discharge is known to provide stability to an organism and predict changes on external instigation, but how brain analyses external cues during active motion has not yet been studied in detail. ${ }^{4)}$ Also, studies have found superior-colliculus-mediodorsal thalamus frontal eye-field pathway as an important corollary discharge circuitry. However, further research is required to assess the contribution of this pathway to corollary discharge dysfunction especially with regards to pathogenesis of symptoms and disorder. ${ }^{28)}$

Though the dysfunction of corollary discharge has been studied in several disorders, the exact circuits are yet to be elucidated definitively. Further research at the cellular and molecular level of corollary discharge phenomena and yield to better understanding of its mechanistic basis of action. Research on the developmental aspects of corollary discharge feedback circuits is warranted to facilitate insight into the genetic component of feed forward dysfunction model of psychopathology. Studies are required to delineate if there are different types of corollary discharge circuits employed for different modalities, or one particular corollary discharge circuit is meant for one typical function.

Since the exact neural circuitry basis of corollary discharge induced cortical suppression is yet to be delineated, it is difficult to rule out confounding concurrent processes. For example, let's consider cortical suppression during talking out loud. ${ }^{50)}$ Active talk involves a) con- 
traction of the temporalis muscle that spans over the frontal-temporal region and b) demands more attention than passive. The contribution of these factors to cortical suppression needs to be examined so that contribution of corollary discharge to cortical suppression could be established. ${ }^{77)}$ Advanced brain imaging techniques can answer such questions by allowing examination of neural circuits specific to corollary discharge by studying the interplay between different brain structures. ${ }^{78)}$

\section{CONCLUSION}

The purpose of this review was to elucidate neural basis of corollary discharge phenomena, summarize existing research on it, and build arguments that support its candidature for explaining schizophrenia symptoms with focus on auditory hallucinations. To this extent, neurophysiological, neuroanatomical and neurochemical explanations of mechanistic basis of corollary discharge phenomena were reviewed and examined. ${ }^{8,28)}$

Corollary discharge is integral to the ability of an organism to recognize itself and its own actions like proprioception ${ }^{1)}$ and underlies highest forms of neural assessments like thought and ipseity. ${ }^{7)}$ Contribution of corollary discharge in attenuation of sensory feedback arising from the self-generated activity of the organism is imperative and unambiguous. ${ }^{50)}$ Extensively studied in audition ${ }^{51)}$ proprioception, ${ }^{1)}$ and higher motor complex process like thought, ${ }^{8)}$ corollary discharge of thought in healthy brain involves attenuation of auditory cortex, the somatosensory cortex and thalamus, as a result of match between the efference copy and sensory re-afference. This essentially gives the organism a feeling of 'self'. Another important utility of corollary discharge is its role in predictive functions; like visual stability continues to be because of corollary discharge phenomena. To enable this, the corollary discharge signals anticipate extra retinal pre saccades before they occur, and corollary discharge signal thusly keep an organism prepared for the change in field of vision. ${ }^{79)}$ Corollary discharge is implicated in learning and memory processes as well and it helps an organism in self-monitoring in skill acquisition phase using the copies of corollary discharge stored in it memory to make better approximations of intended activity. ${ }^{1)}$ A deficiency in corollary discharge thus manifests as altered in perceptual experiences (dreams and hallucinations), disrupted sense of self (schizophrenia), difficulty in learning and memory (source monitoring) and other cognitive problems. Extensively studied in schizophrenia in the context of auditory hallucinations, neurophysiological and neuroimaging findings on corollary discharge establish that its dysfunction plays a crucial role in hallucination pathophysiology. ${ }^{9)}$ However, to ascertain contribution of corollary discharge to other symptoms of schizophrenia like delusion and disorganization ${ }^{8)}$ robust empirical evidences are required. With reports of correction of corollary discharge deficiency with tDCS neuromodulation, a new avenue for examination of its neural circuitry, role in psychiatric symptoms and contribution dream/sleep-related experiences opens up. As schizophrenia manifests as disruption of the self, understanding of schizophrenia aetiology can benefit from deeper exploration of corollary discharge phenomena that is integral to the experience of the self.

\section{- Acknowledgments}

This work is supported by the Swarnajayanti Fellowship Grant of the Department of Science and Technology (Government of India) to Ganesan Venkatasubramanian (DST/SJF/LSA-02/2014-15). Rujuta Parlikar and Anushree Bose are supported by the Swarnajayanti Fellowship Grant (DST/SJF/LSA-02/2014-15).

\section{REFERENCES}

1. Crapse TB, Sommer MA. Corollary discharge across the animal kingdom. Nat Rev Neurosci 2008;9:587-600.

2. Aliu SO, Houde JF, Nagarajan SS. Motor-induced suppression of the auditory cortex. J Cogn Neurosci 2009;21:791-802.

3. Lindner A, Thier P, Kircher TT, Haarmeier T, Leube DT. Disorders of agency in schizophrenia correlate with an inability to compensate for the sensory consequences of actions. Curr Biol 2005; 15:1119-1124.

4. Carriot J, Brooks JX, Cullen KE. Multimodal integration of self-motion cues in the vestibular system: active versus passive translations. J Neurosci 2013;33:19555-19566.

5. Ford JM, Mathalon DH. Anticipating the future: automatic prediction failures in schizophrenia. Int J Psychophysiol 2012;83:232-239.

6. Bellebaum C, Daum I, Koch B, Schwarz M, Hoffmann KP. The role of the human thalamus in processing corollary discharge. Brain 2005; 128:1139-1154.

7. Jackson JH, Taylor J, Holmes G, Walshe F. Selected writings of John Hughlings Jackson. London:Staples Press; 1958.

8. Taylor JG. A neural model of the loss of self in schizophrenia. Schizophr Bull 2011;37:1229-1247. 
9. Ford JM. Studying auditory verbal hallucinations using the RDoC framework. Psychophysiology 2016;53:298-304.

10. Ford JM, Palzes VA, Roach BJ, Mathalon DH. Did I do that? Abnormal predictive processes in schizophrenia when button pressing to deliver a tone. Schizophr Bull 2014;40:804-812.

11. Sperry RW. Neural basis of the spontaneous optokinetic response produced by visual inversion. J Comp Physiol Psychol 1950;43:482-489.

12. Von Holst $\mathrm{E}$, Mittlestaedt $\mathrm{H}$. The principle of reafference: interactions between the central nervous system and the peripheral organs. Die Naturwissenschften 1950;37:464-476.

13. Evarts EV. Central control of movement. V. Feedback and corollary discharge: a merging of the concepts. Neurosci Res Program Bull 1971;9:86-112.

14. Scott Kelso JA. Planning and efferent components in the coding of movement. J Mot Behav 1977;9:33-47.

15. Feinberg I. Efference copy and corollary discharge: implications for thinking and its disorders. Schizophr Bull 1978; 4:636-640.

16. Guthrie BL, Porter JD, Sparks DL. Corollary discharge provides accurate eye position information to the oculomotor system. Science 1983;221:1193-1195.

17. Kuthan V. Some contributions of I.E. Purkynĕ to the visual physiology. Physiol Bohemoslov 1987;36:255-267.

18. Duhamel JR, Colby CL, Goldberg ME. The updating of the representation of visual space in parietal cortex by intended eye movements. Science 1992;255:90-92.

19. Grüsser OJ. Early concepts on efference copy and reafference. Behav Brain Sci 1994;17:262-265.

20. Wolpert DM, Miall RC. Forward models for physiological motor control. Neural Netw 1996;9:1265-1279.

21. Poulet JF, Hedwig B. The cellular basis of a corollary discharge. Science 2006;311:518-522.

22. Guillery RW, Sherman SM. Branched thalamic afferents: what are the messages that they relay to the cortex? Brain Res Rev 2011;66:205-219.

23. Ford JM, Gray M, Faustman WO, Heinks TH, Mathalon DH. Reduced gamma-band coherence to distorted feedback during speech when what you say is not what you hear. Int J Psychophysiol 2005;57:143-150.

24. Chen CM, Mathalon DH, Roach BJ, Cavus I, Spencer DD, Ford JM. The corollary discharge in humans is related to synchronous neural oscillations. J Cogn Neurosci 2011;23:28922904.

25. Pynn LK, DeSouza JF. The function of efference copy signals: implications for symptoms of schizophrenia. Vision Res 2013;76:124-133.

26. Blakemore SJ, Smith J, Steel R, Johnstone CE, Frith CD. The perception of self-produced sensory stimuli in patients with auditory hallucinations and passivity experiences: evidence for a breakdown in self-monitoring. Psychol Med 2000;30: 1131-1139.

27. Creutzfeldt O, Ojemann G, Lettich E. Neuronal activity in the human lateral temporal lobe. II. Responses to the subjects own voice. Exp Brain Res 1989;77:476-489.

28. Sommer MA, Wurtz RH. What the brain stem tells the frontal cortex. II. Role of the SC-MD-FEF pathway in corollary discharge. J Neurophysiol 2004;91:1403-1423.

29. Grace AA. Hippocampal dysregulation of dopamine system activity as a pathophysiological basis for psychosis in schizophrenia. Clin Psychopharmacol Neurosci 2010;8:1-9.

30. Whitford TJ, Ford JM, Mathalon DH, Kubicki M, Shenton ME. Schizophrenia, myelination, and delayed corollary discharges: a hypothesis. Schizophr Bull 2012;38:486-494.

31. Sarter M, Nelson CL, Bruno JP. Cortical cholinergic transmission and cortical information processing in schizophrenia. Schizophr Bull 2005;31:117-138.

32. Schneider DM, Mooney R. Motor-related signals in the auditory system for listening and learning. Curr Opin Neurobiol 2015;33:78-84.

33. Thiel CM, Bentley P, Dolan RJ. Effects of cholinergic enhancement on conditioning-related responses in human auditory cortex. Eur J Neurosci 2002;16:2199-2206.

34. More SV, Choi DK. Emerging preclinical pharmacological targets for Parkinson's disease. Oncotarget 2016;7:2983529863.

35. Rickards C, Cody FW. Proprioceptive control of wrist movements in Parkinson's disease. Reduced muscle vibration-induced errors. Brain 1997;120:977-990.

36. Glickstein M, Waller J, Baizer JS, Brown B, Timmann D. Cerebellum lesions and finger use. Cerebellum 2005;4:189197.

37. Sala SD, Marchetti C. Disentangling the alien and anarchic hand. Cogn Neuropsychiatry 1998;3:191-207.

38. Lhermitte F. Human autonomy and the frontal lobes. Part II: patient behavior in complex and social situations: the "environmental dependency syndrome". Ann Neurol 1986; 19:335-343.

39. Feinberg TE, Schindler RJ, Flanagan NG, Haber LD. Two alien hand syndromes. Neurology 1992;42:19-24.

40. Moore JW, Fletcher PC. Sense of agency in health and disease: a review of cue integration approaches. Conscious Cogn 2012;21:59-68.

41. Eldridge FL, Paydarfar D. Desynchronized respiratory rhythms and their interactions in cats with split brain stems. J Physiol 1989;410:513-532.

42. Zeng $\mathrm{H}, \mathrm{Wu}$ X. Alzheimer's disease drug development based on computer-aided drug design. Eur J Med Chem 2016;121: 851-863.

43. Selkoe DJ. Alzheimer's disease is a synaptic failure. Science 2002;298:789-791.

44. Machado S, Cunha M, Minc D, Portella CE, Velasques B, Basile LF, et al. Alzheimer's disease and implicit memory. Arq Neuropsiquiatr 2009;67:334-342.

45. Eldridge LL, Masterman D, Knowlton BJ. Intact implicit habit learning in Alzheimer's disease. Behav Neurosci 2002;116: 
722-726.

46. Velasques B, Machado S, Paes F, Cunha M, Sanfim A, Budde $\mathrm{H}$, et al. Sensorimotor integration and psychopathology: motor control abnormalities related to psychiatric disorders. World J Biol Psychiatry 2011;12:560-573.

47. Autism and Developmental Disabilities Monitoring Network Surveillance Year 2006 Principal Investigators; Centers for Disease Control and Prevention (CDC). Prevalence of autism spectrum disorders - Autism and Developmental Disabilities Monitoring Network, United States, 2006. MMWR Surveill Summ 2009;58:1-20.

48. Zhang XQ, Wang ZM, Pan YL, Chiu HF, Ng CH, Ungvari GS, et al. Use of electroconvulsive therapy in older Chinese psychiatric patients. Int I Geriatr Psychiatry 2015;30:851-856.

49. Frith C. Functional imaging and cognitive abnormalities. Lancet 1995;346:615-620.

50. Shergill SS, White TP, Joyce DW, Bays PM, Wolpert DM, Frith CD. Functional magnetic resonance imaging of impaired sensory prediction in schizophrenia. JAMA Psychiatry 2014;71: 28-35.

51. Ford JM, Mathalon DH. Corollary discharge dysfunction in schizophrenia: can it explain auditory hallucinations? Int J Psychophysiol 2005;58:179-189.

52. Ford JM, Mathalon DH. Electrophysiological evidence of corollary discharge dysfunction in schizophrenia during talking and thinking. I Psychiatr Res 2004;38:37-46.

53. Perez VB, Ford JM, Roach BJ, Loewy RL, Stuart BK, Vinogradov $\mathrm{S}$, et al. Auditory cortex responsiveness during talking and listening: early illness schizophrenia and patients at clinical high-risk for psychosis. Schizophr Bull 2012;38: 1216-1224.

54. Spering M, Dias EC, Sanchez JL, Schütz AC, Javitt DC. Efference copy failure during smooth pursuit eye movements in schizophrenia. J Neurosci 2013;33:11779-11787.

55. Sass LA, Parnas J. Schizophrenia, consciousness, and the self. Schizophr Bull 2003;29:427-444.

56. Woo TU. Neurobiology of schizophrenia onset. Curr Top Behav Neurosci 2014; 16:267-295.

57. Kiran C, Chaudhury S. Understanding delusions. Ind Psychiatry J 2009;18:3-18.

58. Gray JA, Feldon J, Rawlins JNP, Hemsley DR, Smith AD. The neuropsychology of schizophrenia. Behav Brain Sci 1991;14: 1-20.

59. Kapur S. Psychosis as a state of aberrant salience: a framework linking biology, phenomenology, and pharmacology in schizophrenia. Am J Psychiatry 2003;160:13-23.

60. Maher BA. Delusional thinking and perceptual disorder. J Individ Psychol 1974;30:98-113.

61. Mcghie A, Chapman J. Disorders of attention and perception in early schizophrenia. Br J Med Psychol 1961;34:103-116.

62. Jaspers K. General psychopathology. Manchester:Manchester University Press; 1963.

63. Corlett PR, Taylor JR, Wang XJ, Fletcher PC, Krystal JH.
Toward a neurobiology of delusions. Prog Neurobiol 2010; 92:345-369.

64. Gray DM. Failing to self-ascribe thought and motion: towards a three-factor account of passivity symptoms in schizophrenia. Schizophr Res 2014;152:28-32.

65. Hirjak D, Breyer T, Thomann PA, Fuchs T. Disturbance of intentionality: a phenomenological study of body-affecting first-rank symptoms in schizophrenia. PLoS One 2013;8: e73662.

66. Blakemore SJ, Frith C. Disorders of self-monitoring and the symptoms of schizophrenia. In: Kircher T, David A, editors. The self in neuroscience and psychiatry. Cambridge:Cambridge University Press;2003. p.407-424.

67. Mellor CS. First rank symptoms of schizophrenia. I. The frequnncy in schizophrenics on admission to hospital. II. Differences between individual first rank symptoms. $\mathrm{Br} J$ Psychiatry 1970;117:15-23.

68. Waters F, Blom JD, Dang-Vu TT, Cheyne AJ, Alderson-Day B, Woodruff $\mathrm{P}$, et al. What is the link between hallucinations, dreams, and hypnagogic-hypnopompic experiences? Schizophr Bull 2016;42:1098-1109.

69. Feinberg I. Corollary discharge, hallucinations, and dreaming. Schizophr Bull 2011;37:1-3.

70. Perry E, Walker M, Grace J, Perry R. Acety/choline in mind: a neurotransmitter correlate of consciousness? Trends NeurosCi 1999;22:273-280.

71. Agarwal SM, Shivakumar V, Bose A, Subramaniam A, Nawani $\mathrm{H}$, Chhabra $\mathrm{H}$, et al. Transcranial direct current stimulation in schizophrenia. Clin Psychopharmacol Neurosci 2013;11: 118-125.

72. Brunelin J, Mondino M, Gassab L, Haesebaert F, Gaha L, Suaud-Chagny MF, et al. Examining transcranial direct-current stimulation (tDCS) as a treatment for hallucinations in schizophrenia. Am J Psychiatry 2012;169:719-724.

73. Bose A, Shivakumar V, Agarwal SM, Kalmady SV, Shenoy S, Sreeraj VS, et al. Efficacy of fronto-temporal transcranial direct current stimulation for refractory auditory verbal hallucinations in schizophrenia: a randomized, double-blind, sham-controlled study. Schizophr Res 2018;195:475-480.

74. Nawani H, Bose A, Agarwal SM, Shivakumar V, Chhabra H, Subramaniam A, et al. Modulation of corollary discharge dysfunction in schizophrenia by tDCS: preliminary evidence. Brain Stimul 2014;7:486-488.

75. Bose A, Nawani H, Agarwal SM, Shivakumar V, Narayanaswamy JC, Kumar D, et al. Effect of fronto-temporal transcranial direct current stimulation on corollary discharge in schizophrenia: a randomized, double-blind, sham-controlled study. Brain Stimul 2017;10:411.

76. Nawani H, Kalmady SV, Bose A, Shivakumar V, Rakesh G, Subramaniam A, et al. Neural basis of tDCS effects on auditory verbal hallucinations in schizophrenia: a case report evidence for cortical neuroplasticity modulation. J ECT 2014;30: e2-e4.

77. Reznik D, Henkin Y, Schadel N, Mukamel R. Lateralized en- 
hancement of auditory cortex activity and increased sensitivity to self-generated sounds. Nat Commun 2014;5:4059.

78. Leube DT, Knoblich G, Erb M, Schlotterbeck P, Kircher TT. The neural basis of disturbed efference copy mechanism in patients with schizophrenia. Cogn Neurosci 2010;1:111-117.

79. Sommer MA, Wurtz RH. A pathway in primate brain for internal monitoring of movements. Science 2002;296:14801482. 